\title{
Peering into the crystal ball of the disengaged: What happens to students that do not submit an early assessment item?
}

\author{
Kelly Linden \\ Charles Sturt \\ University
}

\author{
Neil Van Der Ploeg \\ Charles Sturt \\ University
}

\author{
Ben Hicks \\ Charles Sturt \\ University
}

\author{
Prue Gonzalez \\ Charles Sturt \\ University
}

\begin{abstract}
Established first year design principles highlight the need to provide early response systems for students who appear to be disengaging with targeted communication regarding available support services. One thousand, one hundred and s students were identified in session 1 that either: did not submit a pre-census early assessment item; or had limited learning management system activity. These students were then offered timely support, including on-the-spot advice and referral to other pre-existing support structures within the University. Students were identified from 77 subjects offered to commencing students, taught across 182 offerings. Of the students identified, 607 chose to defer or withdraw from their studies while 554 students remained. This raises the question, what became of those remaining students?
\end{abstract}

Keywords: Learning analytics, engagement, retention, early assessment items.

\section{Introduction}

The expansion of participation in Higher Education has resulted in an increasing number of students from nontraditional backgrounds undertaking tertiary studies (Edwards \& McMillan, 2015; Stone, 2019). This increased participation has coincided with an exponential growth in online education (Stone, 2019) which offers these students the opportunity to be able to study a university degree. However, despite a widening participation agenda and the introduction of new flexible modes of learning, the literature indicates that institutions find it difficult to provide the right environment for these students to be successful (McKay \& Devlin, 2014; van der Meer et al., 2018). Wider literature argues that for this group to be successful, Universities need to develop targeted programs and support mechanisms that recognise the challenges that are faced by students from a low socioeconomic status (SES) background (Cardak et al., 2017; van der Meer et al., 2018).

Established First Year design principles highlight the need to provide early response systems, with targeted communication regarding available support services, for students who appear to be disengaging (Kift, 2008; van der Meer et al., 2018). Many retention programs implement timely student contact through a range of communication tactics: Outreach calling teams, SMS, Electronic Mailer, and Learning Management Systems (LMS) notifications. Despite many Universities establishing this functionality to support retention, little is known about the specific details of what is effective, particularly in the context of low SES students.

Assessment and feedback drive student learning in higher education and students frequently use assessment to define what is important in the curriculum. Early assessments can help to engage students with the subject in the early weeks of the teaching session when they provide an opportunity for students to complete tasks that help them transition from previous educational experiences into university study. At the same time, early assessment can help identify students who are not engaged in the subject and are thus at risk of failure or withdrawal. This is especially important for online students who may have reduced contact with staff or students (Kift, 2009; Kift \& Moody, 2009).

There is a multitude of published studies describing complex algorithms and models that predict (with varying levels of accuracy) the likelihood of a student failing their subjects or leaving University (Wolff et al., 2013; Lacave et al., 2018; Lu et al., 2018; Tempelaar et al., 2018). One constant throughout these studies is the difficulty in modelling the myriad interactions between learners and learning design as well as the challenge, possibly insurmountable, in finding a one-size-fits all model to apply at scale. Approaching from a complex systems perspective can lead to promising results by applying simple rules that take into account a carefully chosen mix of data (Foster \& Siddle, 2019).

A key finding from a Charles Sturt University pilot study (Linden \& Webster, 2019) was the critical importance of a pre-census assessment item. The use of learning analytics alone as a "trigger" to identify and contact disengaged students simply did not perform as well in terms of improving overall subject progress rates. It is clear that incorporation of such an early, low stakes assessment item is aligned with established first year design principles and 
can be used as a key measure of student engagement. The aim of this project is to investigate what happens to students that do not submit an early, pre-census assessment item; and monitor progress across the first year of enrolment.

\section{Methods}

In session 1 of 2019 a university-wide system was established that identified disengaged students in the critical census period. Seventy-seven subjects from across the 3 Faculties were included in the project, which encompassed almost all commencing undergraduate students enrolled in session 1 of 2019. The engagement of 12, 673 students was monitored and the 1161 students identified as disengaged were proactively contacted and offered on-the-spot advice and referral to a variety of support services.

\section{Student disengagement triggers}

Student disengagement was detected using one of two 'triggers': non submission of an early, pre-census assessment item, and for the subjects without an adequately timed assessment, the level of LMS activity. The value of the early assessment items ranged from $0.7 \%$ to $20 \%$ and had to be due in Week 3 or Week 4 (prior to the census date on the Friday of week 4). For subjects without an early assessment item LMS activity was used to indicate student disengagement by combining a variety of metrics to create a picture of the student. These included: the number of subject outline accesses and the number and recency of subject LMS site log-ins.

Following the due date for each early assessment item a list of students who did not submit the task was generated by the Retention Team either from the LMS directly or from the subject coordinator. If accessed from the LMS, the lists were cross-checked by teaching staff. Once checked, the call lists were forwarded to the Student Outreach Team to make contact with the students.

\section{Contact process}

The Student Outreach Team (comprised of trained current university students) phoned students during business hours throughout Weeks 3 and 4 of session 1. If the first call was not answered, a second call was made the following day (or several hours later if the following day was not possible). If neither call was answered, an email was sent to the student that: notified them of the attempted contact, linked to support services and explained the importance of the census date. Where phone contact was successful, the Outreach Team discussed the missed assessment and offered assistance in the form of on-the-spot advice, or links to other support services as appropriate. The exact content of the conversations was varied and hence difficult to summarise; improvements in documentation and reporting of each call/contact will enable thematic analyses to be conducted in the future.

\section{Findings \& Discussion}

One thousand one hundred and sixty-one students were identified as disengaged by the Retention Team and placed on the calling list for contact by the Outreach Team. The team spoke with $19 \%$ of these students $(n=254)$ over the phone. Of the 1161 students, $61 \%(n=704)$ were commencing their studies in session 1 and; $31 \%(n=356)$ were from low SES backgrounds based on their postcode of primary residence (or prior residence if recently moved to study). This was considerably higher than the proportion of low SES students in the whole cohort $(26 \%)$.

\section{Comparing Submission vs Non Submission of Early Assessment Items}

Subject performance of 7218 students enrolled in the 49 subjects that included an early assessment item and is represented below in Figure 1. This includes all students; those that did submit the early assessment item (Figure 1), and those that did not (Figure 1). Of note is the high number of student withdrawals (WD) prior to the census, irrespective of early assessment item submission. This supports data from earlier pilot studies that indicated that a high proportion of students are still updating their subject enrolments in Weeks 1 and 2 of session (Linden \& Webster, 2019), leading to difficulty in identifying students who are genuinely disengaging. Literature shows the efficacy of 'at-risk' models to accurately determine student disengagement with only two weeks of data is very poor (Kuzilek et al., 2015; Foster \& Siddle, 2019). It is therefore important not to target campaigns too early. Of the approximately 6,500 students that did submit the early assessment item, only a small proportion failed, and the vast majority scored a passing grade (Figure 1). 

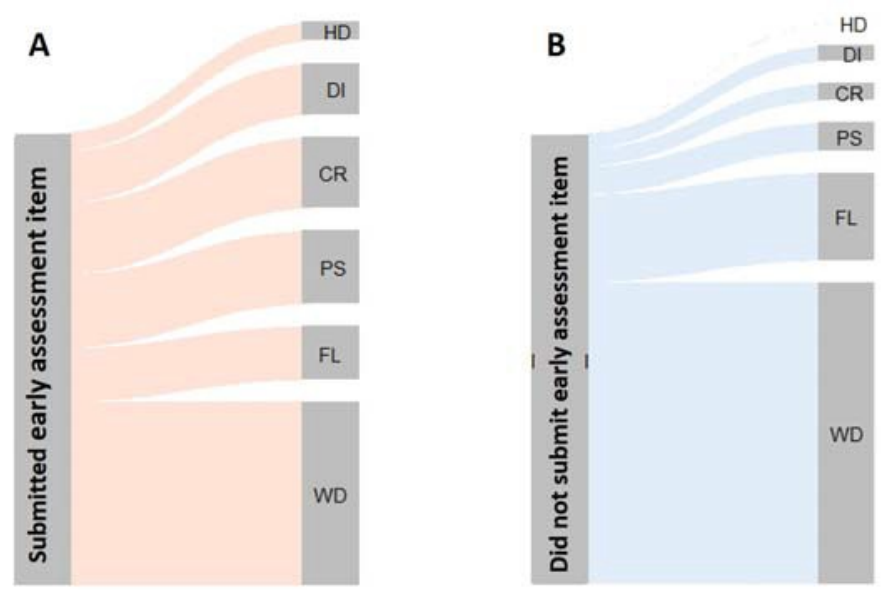

Figure 1. Grades of all 7218 students enrolled in subjects with an early assessment item. Approximately 6,500 students submitted an early assessment item (left) and 718 students did not submit the early assessment (right)

Of the 718 students identified as disengaged from non-submission of an early assessment item in session 1, 46\% $(n=340)$ enrolled in subjects in session 2 . However, only $13 \%(n=90)$ of students remained after the session 2 census date and only $6 \%(n=44)$ went on to pass all subjects in session $2(n=44)$. This further strengthens the case for using this method as part of a university's targeted support service strategy.

\section{Comparing Methods of Identifying Disengaged Students}

When comparing the two "triggers" for identifying disengaged students pre-census, the results from this study demonstrate that non submission of an early assessment item is more accurate than LMS access, particularly for commencing students who have no prior academic history (Table 1). This is supported by Wolff et al. (2014), who found that failure, including non-submission of the first assessment item, was the most important aspect of academic performance data in developing a university wide at-risk model.

\section{Outcomes of Disengaged Students}

Of all the disengaged students identified through both methods, $24 \%$ went on to pass the subject and $22 \%$ of students received a fail grade (Table 1). Six hundred and seven students (51\%) altered their enrolment by either removing the subject for which they were identified, deferring their study, or withdrawing from the University. If students are supported to make a well-informed decision about their enrolment prior to the census date, it is widely accepted that many will avoid unnecessary fail grades and student debt (Cherastidtham \& Norton, 2018; Barnes, Macalpine \& Munro, 2012; Department of Education and Training, 2017).

Table 1. Subject grades for students identified as disengaged via non-submission of an early assessment item and via no/limited LMS activity

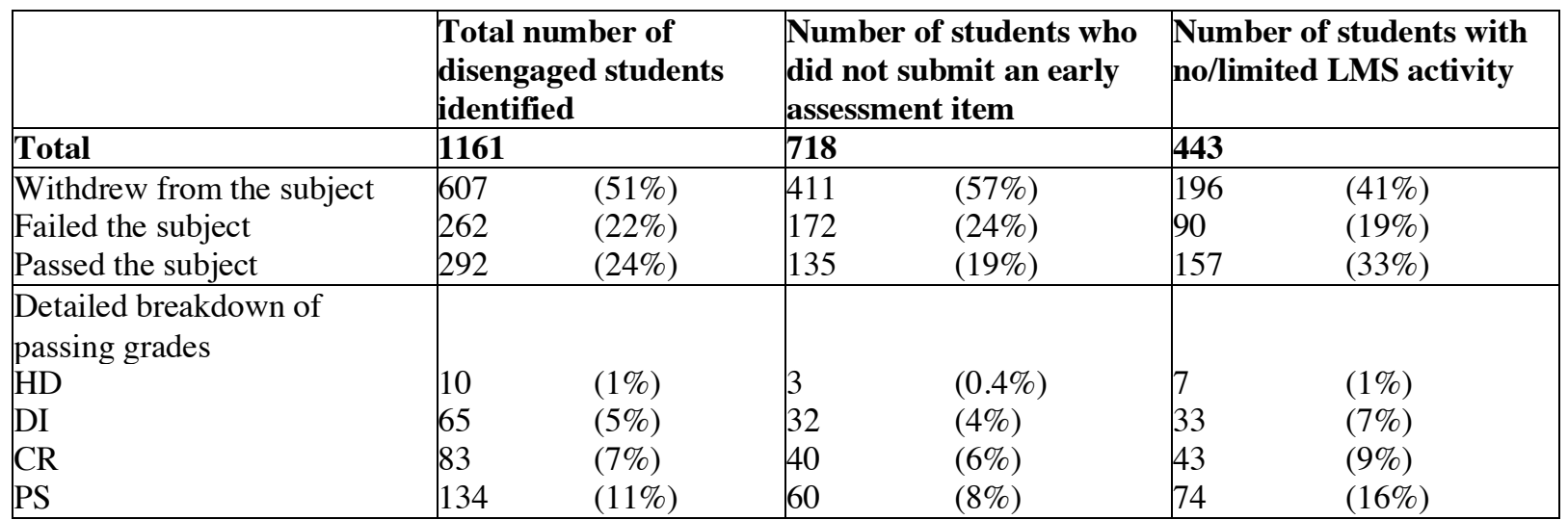




\section{Comparing Types of Early Assessments}

Of the subjects that included a pre-census early assessment item, assessments could be divided into two broad categories: an assignment that involved a writing task $(\mathrm{n}=21$ subjects), or an online multiple choice quiz $(\mathrm{n}=21$ subjects). The weighting of early assessment items was highly variable ranging from $0.7 \%$ to $20 \%$. The writing tasks tended to have a higher weighting and required more effort than online quizzes. The 411 students who withdrew from the subject following non-submission of the early assessment item were almost equally divided into the written task group (48\%) and the online quiz group (52\%). This suggests that the assessment type and weight did not play a significant role in the students' decision to leave the subject. Very similar results are seen when the groups of passing and failing students are interrogated (Table 2). These findings warrant deeper analysis and interpretation; however, this initial analysis seems to indicate that the type and value of an early assessment item are not critical in determining student engagement in the pre-census period.

Table 2. The proportion of students identified as disengaged due to non-submission of a written task, compared with non-submission of an online quiz

\begin{tabular}{|c|c|c|c|}
\hline & $\begin{array}{l}\text { Number of disengaged } \\
\text { students who passed the } \\
\text { subject }\end{array}$ & $\begin{array}{l}\text { Number of disengaged } \\
\text { students who failed the } \\
\text { subject }\end{array}$ & $\begin{array}{l}\text { Number of disengaged } \\
\text { students who withdrew } \\
\text { from the subject }\end{array}$ \\
\hline $\begin{array}{l}\text { Number of students who } \\
\text { did not submit written task }\end{array}$ & $71 \quad(52 \%)$ & $(50 \%)$ & $198 \quad(48 \%)$ \\
\hline $\begin{array}{l}\text { Number of students who } \\
\text { did not submit online quiz }\end{array}$ & $(48 \%)$ & $(50 \%)$ & $(52 \%)$ \\
\hline $\begin{array}{l}\text { Total number of disengaged } \\
\text { students }\end{array}$ & 135 & 172 & 411 \\
\hline
\end{tabular}

\section{Successful Contact and Differing Outcomes}

Nineteen percent of students $(\mathrm{n}=135)$ who did not submit the early assessment item were spoken to over the phone by the Outreach Team (Table 3). These students had a significantly higher likelihood of passing the subject compared to those who did not answer the call (35\% vs $15 \%$ respectively, Table 3 ). This is consistent with research involving a similar targeted support program by Barnes, Macalpine and Munro (2012). Whether this is a direct result of the contact or perhaps related to inherent characteristics of the students who answer the call, versus those who do not, is impossible to know. Regardless, increasing contact success rate with disengaged students should be attempted in order to improve progress rates.

Table 3. Deeper analysis into academic outcomes of students who did not submit an early assessment item. Grade distribution comparison between those who spoke with the calling team compared with those who did not speak with the calling team

\begin{tabular}{|l|l|l|}
\hline & Spoke with calling team & Did not speak with calling team \\
\hline Total & 135 & 583 \\
\hline Pass & $47(35 \%)$ & $88(15 \%)$ \\
Fail & $37(27 \%)$ & $135(23 \%)$ \\
Withdrew & $51(38 \%)$ & $360(62 \%)$ \\
\hline
\end{tabular}

\section{Conclusion}

This study provides further evidence that pre-census assessment items, used in Week 3 and 4, are effective at identifying disengaged students for the purpose of targeted student support to improve retention and should be included in student at risk models. Initial analysis suggests that the type and value of the assessment does not seem to matter when used to identify disengaged students. We found that students are more likely to re-engage and have better academic outcomes if they speak with trained outreach staff members. Therefore, further research is warranted into innovative ways of maximising successful student contact with the disengaged, such as two way SMS. We propose that incorporating synergistic overlay of the curriculum (through early assessment) and student support in the precensus window is a way to improve retention. 


\section{References}

Barnes, S., Macalpine, G., \& Munro, A. (2015). Track and Connect: Enhancing student retention and success at the University of Sydney. A Practice Report. The International Journal of the First Year in Higher Education, 6(1), 195-202.

Cardak, B., Brett, M., Bowden, M., Vecci, J., Barry, P., Bahtsevanoglou, J. and McAllister, R. (2017). Regional Student Participation and Migration: Analysis of factors influencing regional student participation and internal migration in Australian higher education. Perth WA: National Centre for Student Equity in Higher Education, Curtin University.

Cherastidtham, I., \& Norton, A. (2018). University attrition: what helps and what hinders university completion? Grattan Institute Background Paper No. 2018, November. Retrieved from https:/grattan.edu.au/wp-content/uploads/2018/04/University-attrition-background.pdf

Department of Education \& Training. (2017). Improving retention, completion and success in higher education.

Higher Education Standards Panel Discussion Paper, June. Retrieved from https://docs.education.gov.au/system/files/doc/other/final discussion_paper.pdf

Edwards, D., \& McMillan, J. (2015). Completing university in a growing sector: Is equity an issue? Australia: Australian Council for Educational Research.

Foster, F., \& Siddle, R. (2019). The effectiveness of learning analytics for identifying at-risk students in higher education. Assessment \& Evaluation in Higher Education, 6 November. https://doi.org/10.1080/02602938.2019.1682118

Kift, S. (2009). Articulating a transition pedagogy to scaffold and to enhance the first year student learning experience in Australian higher education. Final Report for ALTC Senior Fellowship Program.

Kift, S. M. (2008). The next, great first year challenge: Sustaining, coordinating and embedding coherent institution-wide approaches to enact the FYE as “everybody's business”. In 11th International Pacific Rim First Year in Higher Education Conference, An Apple for the Learner: Celebrating the First Year Experience, Hobart.

Kift, S. M., \& Moody, K. E. (2009). Harnessing assessment and feedback in the first year to support learning success, engagement and retention. In: ATN Assessment Conference 2009 Proceedings, 2009, RMIT University, Melbourne.

Kuzilek, J., Hlosta, M., Herrmannova, D., Zdrahal, Z., Vaclavek, J., \& Wolff, A. (2015). OU Analyse: Analysing at-Risk Students at The Open University. Learning Analytics Review LAK, 15(1), 1-16.

Lacave, C., Molina, A. I., \& Cruz-Lemus, J. A. (2018). Learning Analytics to identify dropout factors of Computer Science studies through Bayesian networks. Behaviour \& Information Technology, 37(10-11), 993-1007.

Linden, K., \& Webster, L. (2019). Back to Basics: combining analytics and early assessment with personalised contact to improve student progress [paper presentation]. 36th International Conference on Innovation, Practice and Research in the Use of Educational Technologies in Tertiary Education (ASCILITE). Singapore.

Lu, O., Huang, A., Huang, J., Lin, A., Ogata, H., \& Yang, S. (2018). Applying Learning Analytics for the Early Prediction of Students' Academic Performance in Blended Learning. Journal of Educational Technology \& Society, 21(2), 220-232.

McKay, J., \& Devlin, M. (2014). 'Uni has a different language...to the real world': demystifying academic culture and discourse for students from low socioeconomic backgrounds. Higher Education Research \& Development, 33(5), 949-961.

Stone, C. (2019). Online learning in Australian higher education: Opportunities, challenges and transformations. Student Success, 10(2), 1-11.

Tempelaar, D., Rienties, B., Mittelmeier, J., \& Nguyen, Q. (2018). Student profiling in a dispositional learning analytics application using formative assessment. Computers in Human Behavior, 78, 408-420.

van der Meer, J., Scott, S., \& Pratt, K. (2018). First semester academic performance: The importance of early indicators of non-engagement. Student Success, 9(4), 1-12.

Wolff, A., Zdrahal, Z., Herrmannova, D., Kuzilek, J., \& Hlosta, M. (2014). Developing Predictive Models for Early Detection of At-Risk Students on Distance Learning Modules [Paper presentation]. Machine Learning 
and Learning Analytics Workshop at The 4th International Conference on Learning Analytics and Knowledge (LAK14), 24-28 March. Indianapolis, Indiana, USA.

Wolff, A., Zdrahal, Z., Nikolov, A., \& Pantucek, M. (2013). Improving retention: predicting at-risk students by analysing clicking behaviour in a virtual learning environment. [Paper presentation]. Third International Conference on Learning Analytics and Knowledge.

Linden, K., Van Der Ploeg, N., Hicks, B. \& Gonzalez, P. (2020). Peering into the crystal ball of the disengaged: What happens to students that do not submit an early assessment item? In S. Gregory, S. Warburton, \& M. Parkes (Eds.), ASCILITE's First Virtual Conference. Proceedings ASCILITE 2020 in Armidale (pp. 48-53).

Note: All published papers are refereed, having undergone a double-blind peer-review process.

The author(s) assign a Creative Commons by attribution licence enabling others to distribute, remix, tweak, and build upon their work, even commercially, as long as credit is given to the author(s) for the original creation.

(c) Linden, K., Van Der Ploeg, N., Hicks, B. \& Gonzalez, P. 2020 